\title{
$\begin{array}{ll}\text { Research Square } & \text { Preprints are preliminary reports that have not undergone peer review. }\end{array}$ or referenced by the media as validated information. \\ Earthquake Preparedness of Households and Its Predictors Based on Health Belief Model
}

\section{Masoumeh Rostami-Moez}

Hamadan University of Medical Sciences School of Public Health https://orcid.org/0000-0002-61325947

\section{Mohammad Rabiee-Yeganeh}

Hamadan University of Medical Sciences Medical School

\section{Mohammadreza Shokouhi}

Hamadan University of Medical Sciences School of Nursing and Midwifery

\section{Amin Dosti-Irani}

Hamadan University of Medical Sciences School of Public Health

Forouzan Rezapur-Shahkolai ( $\nabla$ forouzan.rezapour@gmail.com )

https://orcid.org/0000-0001-5049-1109

\section{Research article}

Keywords: Injury, Disaster, Readiness, Self-efficacy, Prevention

Posted Date: December 4th, 2019

DOl: https://doi.org/10.21203/rs.2.18198/v1

License: (c) (i) This work is licensed under a Creative Commons Attribution 4.0 International License. Read Full License

Version of Record: A version of this preprint was published at BMC Public Health on May 8th, 2020. See the published version at https://doi.org/10.1186/s12889-020-08814-2. 


\section{Abstract}

Background: Earthquakes are one of the most destructive natural disasters in which many people are injured, disabled, or dead each year. Although Iran has only one percent of the world's population, its earthquake-related deaths are six percent. Therefore, this study aimed to determine the level of earthquake preparedness of households and its predictors using the Health Belief Model (HBM).

Methods: This study was conducted on 933 households in Hamadan province, located in the west of Iran, in 2019. Multistage random cluster sampling was used for selecting the participants. The inclusion criteria were having at least 18 years old and being able to answer the questions. A questionnaire was used for data collection including earthquake preparedness, awareness of earthquake response, predictors of earthquake preparedness based on the HBM, and demographic information. Analysis of variance, independent t-test, and a linear regression model were used.

Results: The mean age of participants was approximately $38.29 \pm 12.80$ years. Furthermore, $60.83 \%$ of participants had less than post-secondary education. Earthquake preparedness was poor and about $30 \%$. There was a significant relationship between earthquake preparedness and gender, home ownership, marriage status, and previous earthquake experience $(\mathrm{p}<0.001)$. Regarding the HBM constructs, perceived benefits, cues to action, and self-efficacy had significant predictors of earthquake preparedness $(p<0.01)$.

Conclusions: Regarding the low earthquake household preparedness, community intervention for improving households' preparedness for earthquake based on the HBM is recommended. Intervention can be designed considering cues to action, self-efficacy, and perceived benefits.

\section{Introduction}

Earthquakes are one of the most disturbing natural disasters that their occurrence does not recognize the place and time, often occurring suddenly and uncontrollably, causing many physical, psychological, and social damages in human societies ${ }^{1}$. Over the past two decades, 800 million people have been injured by natural disasters. Besides, natural disasters have caused 42 million deaths in the world ${ }^{2}$. Iran is always at risk of earthquakes due to its geographical location on the Alpine-Himalayan orogenic belt ${ }^{3,4}$. More than 70 percent of the major cities in Iran are in the area of major faults. The earthquakes of recent decades have not only caused the deaths of thousands but also have caused massive economic damage and destroyed many cities and villages in the world ${ }^{5,6}$. Although Iran has only one percent of the world population, the earthquake-related deaths are six percent ${ }^{7}$. The disaster management cycle has four phases including mitigation, preparedness, response, and recovery. Preparedness is an important stage in the disaster management cycle. A previous research has shown that the role of people as the most important and largest group has often been neglected in program planning of disaster preparedness and response ${ }^{8}$. 
The Health Belief Model (HBM) describes the decision-making process that individuals use to adopt a health-promoting behavior ${ }^{9}$. Theoretically, in the HBM, perceived susceptibility, perceived severity, perceived benefits, perceived barriers, cues to action, and self-efficacy (the beliefs of individuals in their ability to prepare for disaster) predict behavior $1,9,10$.

There are some studies on earthquake preparedness that have assessed the readiness of individuals based on their knowledge and skills ${ }^{11-13}$. Some studies have also considered structural and nonstructural safety in some cities ${ }^{14}$ and some studies have investigated students' readiness ${ }^{15,16}$. There are a few studies that have used behavior change models in the disaster area ${ }^{5}$. Haraoka and Inal used the health belief model to develop a questionnaire for earthquake preparedness 1,11 .

Previous studies in Iran showed that most households did not have enough readiness and information to cope with the earthquake and had a relatively high vulnerability to possible earthquake hazards ${ }^{17,18}$. Also, one study showed that improving the socioeconomic status was correlated with improving the attitude of people about disaster preparedness ${ }^{13}$. In DeYoung et al. study, earthquake readiness was positively correlated with risk perception, self-efficacy, and trust in information about hazards through media $^{19}$.

This is the first study in Iran that examines the people's preparedness forearthquakes using a behavior change model (HBM) approach. Considering the importance of preparedness of households for dealing with disasters and unexpected hazards, the purpose of this study was to asses the level of preparedness of Hamadan households for earthquake and its predictors using the HBM.

\section{Methods}

This cross-sectional study was carried out in all counties of Hamadan province, in the west of Iran, in 2019. These counties consisted of Hamadan (the capital of Hamadan province), Malayer, Tuyserkan, Nahavand, Razan, Bahar, Kabudarahang, Asadabad, and Famenin. Using the previous study ${ }^{17}$, the estimated sample size was 600 households. Cluster sampling was used for this study and we used the design effect of 1.5 plus 10 percent attrition. Subsequently, the final sample size was estimated 1000 households. The inclusion criteria were having at least 18 years old and being able to answer the questions. The exclusion criteria were incomplete questionnaire or giving up answering the questions.

Participants have been selected by multi-stage random cluster sampling. First, stratified sampling was used for each county based on their urban and rural population. Then, in urban and rural areas, a list of urban health centers or rural health center were listed and one health center was randomly selected in each county. After that, from the list of all households covered by the selected health center, one household was selected by simple random sampling and sampling started taking the clockwise direction of the selected household and continued until recruiting required sample. For selecting urban sample of Hamadan County, we selected one health center from each municipality district by simple random sampling (in Hamadan city, there are four municipality districts). In the next stage, from the list of covered 
households, one household was randomly selected and the sampling was started taking the clockwise direction until achieving the desired sample size in each municipality district.

From each county, a university graduate person was recruited and trained for data collection. The supervision and training was done by the first author. The data was collected from February to July, 2019. Informed consent was obtained from all participants before the data gathering. A person aged 18 or above was randomly selected from each household and answered questions. For illiterate people, questionnaires were filled by interviewing them.

\section{Measurements}

The questionnaire used for data collection comprises four domains including demographics, earthquake preparedness, awareness on earthquake response, and predictor of earthquake preparedness based on the HBM. Demographics included age, sex, occupation, education, economic status, family size, number of individual over 60 years old and under 16, earthquake experience, homeownership, marital status, and ill person in household. In addition to the earthquake preparedness checklist ${ }^{20}$ in yes or no answers, we added two questions to the checklist (do you know the necessary contact numbers such as fire station, police, and emergency so you can call them if needed and are you familiar with the phrase, "Drop, Cover, Hold"?). The score of this checklist was ranging from 0 to 25 and higher score reflects more preparedness.

The awareness questionnaire on earthquake response included seven questions with true/false answers (In an earthquake: you should get down close to the ground; you should get under a big piece of furniture such as a desk or other covers; you should hold on a firm object until the end of the shaking; you should get in a doorway; If you are indoors during an earthquake, you must exit the building; If you are in bed during an earthquake, you should stay there and cover your head with a pillow; next to the pillar of buildings and the interior wall corners are the safe areas). One point was given for each correct answer. Therefore, the total score of this domain was seven points.

The modified questionnaire for the predictor of earthquake preparedness based on the HBM was used. The original questionnaire has been established and validated by Inal et $\mathrm{al}^{1}$ in Turkey. The forward and backward translation method was used for translating original questionnaire. Further, three questions were added to the questions of the cues to action (Radio and TV encourage me to prepare for disasters, I usually get information about disasters preparedness from Radio and TV, I usually get information about disasters preparedness from staff of health centers). Respectively, one question was added to perceived benefits questions (Preparedness for disaster will reduced financial losses and Physical injuries). Then, a panel of experts including 10 Health specialists in disasters and health promotion assessed the content validity of the questionnaires $(\mathrm{CVI}=0.85)$. The reliability of the questionnaire calculated by Cronbach's alpha coefficient in a pilot study on 40 people over 18 years old. A question from the perceived severity (emergency and the experience of disasters does not change my life) and a question of self-efficacy ( cannot create an emergency plan with my neighbors) were excluded by Cronbach's alpha results. Finally, 
the questionnaire consisted of 33 questions including perceived severity ( 2 questions, $a=0.709$ ), perceived susceptibility ( 6 questions, $a=0.664$ ), perceived benefits ( 4 questions, $a=0.758$ ), perceived barriers ( 6 questions, $a=0.822$ ), self-efficacy (7 questions, $a=0.677$ ), and cues to action ( 8 questions, $a=$ 0.683 ). Moreover, all items were ranked by 5 -point Likert scale ranging from 'completely disagree' (one point) to 'completely agree' (5 points).

Analysis of variance (AVOVA) and independent t-test were used to determine the relationship between variables. Linear regression model was used to determine predictors of household earthquake preparedness. The Stata 14.2 software was used to analyze the data. This study was approved by Ethical Committee of Hamadan University of Medical Sciences (Ref. No.: IR.UMSHA.REC.1397.359).

\section{Results}

In this study, 933 questionnaires were analyzed (response rate: 93.3\%). Besides, 228 (24.4\%) participants were male and $656(70 / 31 \%)$ were female. About 80 percent of the participants did not have an academic education and had a diploma degree or less than a diploma degree. Also, 573 (about 61.5\%) participants were homeowners (See Table 1).

The earthquake preparedness of the participants was low. The average household preparedness score was 7.5 out of 25. In other words, the average earthquake preparedness of households was approximately $30 \%$. Besides, the self-efficacy score was $60.79 \pm 0.55$ and the cues to action score was $66.57 \pm 0.45$ (See Table 2).

The participants' preparedness for the earthquake had a significant relationship with gender, homeownership, marital status, education, economic status, and previous experience of a destructive earthquake. The mean score of earthquake preparedness was higher in those who reported moderate and good economic status than other groups, which was statistically significant by the Scheffe test $(p<0.01)$. Also, the Scheffe test showed a significant difference between university education and diploma with illiterate people $(p<0.05)$ and similarly, a significant difference in earthquake preparedness was observed between academic degree and diploma with primary education level $(p<0.01)$ (See Table 3).

Using crude regression, all constructs of HBM except perceived severity had significant predictors of earthquake preparedness $(p<0.001)$, but after using stepwise regression only perceived benefits, cues to action, and self-efficacy significantly predicted the earthquake preparedness $(p<0.001)$.

\section{Discussion}

Despite the strong emphasis on earthquake preparedness and prevention of its damaging effects, the findings of this study showed that most people had low preparedness for earthquakes which is similar to the findings of previous studies ${ }^{16,21-23}$. This can be very dangerous in areas in which they are exposed to earthquakes. Control of the damaging consequences of the earthquake is related to the occurrence of earthquakes in the region and the history of its destruction. Households that had previously experienced 
earthquakes or destructive earthquakes were more prepared than those who had not previously experienced this event, which is similar to previous finding 24,25 . People who live in areas with a history of earthquakes and the subsequent severe damage tend to be more prepared than people living in other areas $^{16}$. This could be due to the recall of previous injuries as well as the fear of recurrence of similar injuries in future earthquakes. This goes back to the culture of the society that people don't believe in hazards occurrence and their consequences until they experience these hazards. Regarding the high frequency of earthquakes in this province, most of the participants in this study had previous earthquake experience but they were not prepared for earthquakes. Perhaps this is because most of the recent earthquakes in Hamadan have not resulted in deaths and as a result, these households do not take the risk of earthquakes seriously and do not find it essential to hold earthquake preparedness meetings ${ }^{26}$. Additionally, preparatory programs may be held, but insufficient and impractical information is provided.

The results of this study showed that education was significantly correlated with household earthquake preparedness, which is similar to the results of the Russell et al. study, and the Qadiri et al. study 27,28 . An explanation can be that people with higher education are more knowledgeable and more aware of earthquakes and its consequences and thus, gain more skills 26,29 .

The results of this study showed that the preparedness of participants has a significant relationship with homeownership and the owners were more prepared for earthquakes than the renters. The results of one study also showed that homeowners had taken more steps to prepare for earthquakes than nonowners ${ }^{30}$. Another study by Alan et al. in 2006 also showed that homeownership was significantly related to disaster preparedness ${ }^{31}$ but a study in Ethiopia in 2014 showed that homeownership had no relationship with disaster preparedness ${ }^{26}$. One of the explanations is that owners can make the necessary changes in spite of preparedness costs due to place attachment but any final conclusion in this regard requires further research.

This study showed that perceived benefit, cues to action, and self-efficacy had a significant relationship with earthquake preparedness. The possibility of people being more prepared for earthquakes increases when they are aware of and understand properly the benefits of being prepared for earthquakes and other disasters. People with high self-efficacy also feel more empowered to take better care of themselves and their families during disasters ${ }^{32}$. Cues to action also encourage earthquake preparedness ${ }^{1}$. Broadcasting can provide programs about earthquake preparedness and educate people about it. The fact that perceived benefits positively and significantly are associated with the household preparedness for earthquake disaster indicates that the perceived benefit was higher than the perceived barrier. Therefore, individuals may perceive the earthquake as too hazardous but they feel confident enough to reduce devastating effects of earthquakes through preparedness and mitigation actions at household level. Similarly, people may perceive earthquake as high threat but in the existence of higher perception of benefits, higher preparedness and self-efficacy can be expected. One possible explanation is that perceived benefits motivate people to perform a behavior and adopt an action. If people perceive benefits as a significant factor for preventing a hazardous action, they will accept to do an appropriate behavior ${ }^{10}$. 
Besides, the significant association of self-efficacy with preparedness at household level for earthquakes could be explained by positive and strong association of cues to actions with earthquake preparedness at household level. Self-efficacy can be improved using peer models and encouragement. Self-efficacy affects one's efforts to change risk behavior and insist on continuing safe behavior despite obstacles that may decline motivation ${ }^{10}$.

This study has some strength, including the use of behavior change models to identify factors that influence earthquake preparedness with a high sample size. But this study also had some limitations due to a few relevant studies on earthquake preparedness based on behavior change models. Therefore, it was less possible to compare different studies to the findings of this study. Generalization of the results of this study to other settings should be done with caution.

Despite these limitations, the findings of this study are useful for emergency service providers, health authorities, and policy makers in designing and implementing earthquake preparedness programs. This research is also useful for researchers as it can be used as a basis for future researches. It is recommended to design and implement interventions to improve household preparedness for earthquake with regard to self-efficacy, perceived benefits and cue to action. The results of this study showed that the earthquake preparedness of the studied households is low. Also, using the HBM to predict the factors for predicting earthquake preparedness is useful. Perceived benefit, cues to action, and self-efficacy were predictors of earthquake preparedness. Therefore, it is necessary to encourage earthquake preparedness by preparing scientific programs with the participation of relevant experts and authorities in addition to using reliable resources. Further intervention should be implemented in order to promote the participants' preparedness for the earthquake.

\section{Conclusion}

Most people had low preparedness for earthquakes. Control of the damaging consequences of earthquakes is related to the preparedness for earthquakes and can prevent its devastating effects. Perceived benefit, cues to action, and self-efficacy had a significant relationship with earthquake preparedness. The possibility of people being more prepared increases when they are aware of and understand properly the benefits of being prepared for earthquakes and other disasters. People with high self-efficacy also feel more empowered for taking better care of themselves and their families during disasters. Cues to action also encourage earthquake preparedness. Since health centers and TV and radio programs were the primary source of learning about earthquakes for the people, it is recommended that broadcasting provides related programs and educates people about earthquake preparedness.

\section{Declarations}

\section{Fund}


This study was approved and financially supported by Deputy of Research and Technology of Hamadan University of Medical Sciences.

\section{Competing interests}

All authors declare that they have no competing interests.

\section{Availability of data and materials}

The datasets used and/or analyzed during this study are available from the corresponding author on reasonable request.

\section{Acknowledgements}

The authors gratefully thank all of the participants in this study.

\section{Authors' contributions}

MR-M has made substantial contributions to the conception and design of the study, took responsibility for and coordinated the acquisition of data and contributed actively in the analysis of the data and in the writing of the manuscript. FR-S and MS contributed to the design of the study and in the writing of the manuscript. MR-Y were closely involved in the data collection process. AD-I contributed to the study design, in the data analysis and results interpretation. All authors read and approved the final manuscript.

\section{References}

1.Inal E, Altintas KH, Dogan N. The development of a general disaster preparedness belief scale using the Health Belief Model as a theoretical framework. International Journal of Assessment Tools in Education. 2018;5(1):146-58.

2.Şakiroğlu M. Variables related to earthquake Preparedness Behavior. Unpublished MS Thesis, Department of Psychology, Middle East Technical University. Ankara: Turkey. 2005.

3.Walters RJ, England P, Houseman G, editors. The dynamics of continental convergence in Iran. AGU Fall Meeting Abstracts; 2016.

4.Bakhtiari A. Country report: the Islamic Republic of Iran on disaster risk management. Kobe: Iranian National Disaster Management Organization. 2014. 
5.Ejeta LT, Ardalan A, Paton D. Application of behavioral theories to disaster and emergency health preparedness: A systematic review. PLoS Curr. 2015;7.

6.Abdolizadeh S, Maleki Z, Arian M. Earthquake Hazard Zonation and Seismotectonics of the Bandar Abbas Area, Zagros, Iran. Open Journal of Geology. 2016;6(03):210.

7.Building, Center HR. Iranian code of practice for seismic resistant design of buildings. 2005.

8.Farajzadeh M, Ghanei Gheshlagh R, Beiramijam M, Dalvand S, Ghawsi S, Amini H. Preparedness of Nurses for Crises and Disasters in Imam Khomeini and Social Security Hospitals of Saqqez. Health in Emergencies and Disasters Quarterly. 2017; 3 (1): 57-63. Use your device to scan and read the article online. 2017;3(1):2.

9.Teitler-Regev S, Shahrabani S, Benzion U. Factors affecting intention among students to be vaccinated forA/H1N1 influenza: a health belief model approach. Adv Prev Med. 2011;2011.

10.Glanz K, Rimer BK, Viswanath K. Health behavior and health education: theory, research, and practice: John Wiley \& Sons; 2008.

11. Haraoka T, Ojima T, Murata C, Hayasaka S. Factors influencing collaborative activities between nonprofessional disaster volunteers and victims of earthquake disasters. PloS one. 2012;7(10):e47203.

12.Cvetković V, Dragičević S, Petrović M, Mijalković S, Jakovljević V, Gačić J. Knowledge and perception of secondary school students in Belgrade about earthquakes as natural disasters. Pol J Environ Stud. 2015;24(4):1553-61.

13.Rezaee M, Lashgari E, Nori M. Evaluation disaster management status of Kerman city with emphasis on mental-attitude preparedness. Hum Geogr Res. 2018;50(4):853-71(persian).

14.Dargahi A, Farrokhi M, Poursadeghiyan M, Ahagh M, Karami A. Evaluation of Functional Preparedness and Non Structural Safety of Different Health Units of Kermanshah University of Medical Sciences in Coping With Natural Disasters. Health in Emergencies and Disasters Quarterly. 2017; 2 (4): 201-206. Use your device to scan and read the article online. 2017;2(4):2.

15.Ronan KR, Alisic E, Towers B, Johnson VA, Johnston DM. Disaster preparedness for children and families: a critical review. Curr Psychiatry Rep. 2015;17(7):58.

16.Amanat N, Khankeh H, Hosseini MA, Mohammadi F, Sadeghi A, Aghighi A. The effect of earthquake preparedness training to male high school students on families' preparedness in Eshtehard city in 20102011. Journal of rescue \& relief 2013;5(3):27 To 39.

17.Rakhshani T, Abbasi S, Ebrahimi M, Travatmanesh S. Investigating the preparedness status of households for earthquakein Fars Province in 2013; A cross sectional study. Iranian Journal of Emergency Medicine. 2016;3(2):66-72. 
18.Jamshidi E, Majdzadeh R, Namin MS, Ardalan A, Majdzadeh B, Seydali E. Effectiveness of community participation in earthquake preparedness: a community-based participatory intervention study of Tehran. Disaster Med Public Health Prep. 2016;10(2):211-8.

19.DeYoung SE. Disaster Preparedness: Psychosocial Predictors for Hazard Readiness. 2014;PhD tesis (Raleigh, North Carolina).

20.Spittal MJ, Walkey FH, McClure J, Siegert RJ, Ballantyne KE. The Earthquake Readiness Scale: the development of a valid and reliable unifactorial measure. Nat Hazards. 2006;39(1):15-29.

21.Rañeses MK, Chang-Richards A, Richards J, Bubb J. Measuring the level of disaster preparedness in Auckland. Procedia Eng. 2018;212:419-26.

22.Ozmen F. The level of preparedness of the schools for disasters from the aspect of the school principals. Disaster Prev Manag. 2006;15(3):383-95.

23.Wu G, Han Z, Xu W, Gong Y. Mapping individuals' earthquake preparedness in China. Natural Hazards and Earth System Sciences. 2018;18(5):1315-25.

24.Shapira S, Aharonson-Daniel L, Bar-Dayan Y. Anticipated behavioral response patterns to an earthquake: The role of personal and household characteristics, risk perception, previous experience and preparedness. Int J Disaster Risk Reduct. 2018;31:1-8.

25.Najafi M, Ardalan A, Akbarisari A, Noorbala AA, Jabbari H. Demographic determinants of disaster preparedness behaviors amongst Tehran inhabitants, Iran. PLoS Curr. 2015;7.

26.Ashenefe B, Wubshet M, Shimeka A. Household flood preparedness and associated factors in the flood-prone community of Dembia district, Amhara National Regional State, northwest Ethiopia. Risk Manag Healthc Policy. 2017;10:95.

27.Russell LA, Goltz JD, Bourque LB. Preparedness and hazard mitigation actions before and after two earthquakes. Environment and behavior. 1995;27(6):744-70.

28.Ghadiri M, Nasabi N. Analysis of the difference of mental-attitude preparedness of earthquake in Shiraz households. Geogr urban Plan Res. 2015;3(2):227-45(persian).

29.Edwards ML. Social location and self-protective behavior: Implications for earthquake preparedness. Int J Mass Emerg Disasters. 1993;11(3):293-303.

30.Oral M, Yenel A, Oral E, Aydin N, Tuncay T. Earthquake experience and preparedness in Turkey. Disaster Prev Manag. 2015;24(1):21-37.

31.Kirschenbaum A. Families and disaster behavior: a reassessment of family preparedness. Int $\mathrm{J}$ Mass Emerg Disasters. 2006;24(1):111. 
32.Paton D. Disaster preparedness: a social-cognitive perspective. Disaster Prev Manag. 2003;12(3):2106.

\section{Tables}

Table 1. Basic and demographic characteristic of participants of earthquake preparedness study

\begin{tabular}{|c|c|c|c|}
\hline Variables & & Mean & $\mathrm{SD}$ \\
\hline Age & & 38.24 & 12.85 \\
\hline Family size & & 3.74 & 1.29 \\
\hline Residential years & & 13.09 & 12.58 \\
\hline Variables & & Number & Percent \\
\hline \multicolumn{4}{|l|}{ Sex } \\
\hline & Man & 228 & 24.44 \\
\hline & Woman & 656 & 70.31 \\
\hline \multicolumn{4}{|l|}{ Education } \\
\hline & Uneducated & 86 & 9.22 \\
\hline & Primary & 216 & 23.15 \\
\hline & Secondary & 187 & 20.04 \\
\hline & High school & 77 & 8.25 \\
\hline & Diploma & 179 & 19.19 \\
\hline & University & 186 & 19.94 \\
\hline \multicolumn{4}{|l|}{ Economic statue } \\
\hline & Good & 65 & 6.97 \\
\hline & Moderate & 387 & 41.48 \\
\hline & Poor & 447 & 48.02 \\
\hline \multicolumn{4}{|l|}{ Owner of the house } \\
\hline & Yes & 573 & 61.41 \\
\hline & No & 313 & 33.55 \\
\hline \multicolumn{4}{|l|}{ Marriage statue } \\
\hline & Married & 812 & 87.03 \\
\hline & Unmarried & 121 & 12.07 \\
\hline \multicolumn{4}{|c|}{ Earthquake experience } \\
\hline & Yes & 744 & 79.74 \\
\hline & No & 136 & 136 \\
\hline \multicolumn{4}{|c|}{ Damaging earthquake experience } \\
\hline & Yes & 66 & 7.07 \\
\hline & No & 822 & 88.10 \\
\hline \multicolumn{4}{|l|}{ Over 60 old } \\
\hline & Yes & 253 & 27.12 \\
\hline & No & 680 & 72.88 \\
\hline \multicolumn{4}{|l|}{ Under 16 old } \\
\hline & Yes & 597 & 63.99 \\
\hline & No & 336 & 36.01 \\
\hline \multicolumn{4}{|l|}{ Ill people in home } \\
\hline & Yes & 194 & 20.79 \\
\hline & No & 736 & 78.89 \\
\hline
\end{tabular}


Table 2. Determining the Average of Preparedness Scores and Structures of Health Belief Model and Performance Awareness of Participants

\begin{tabular}{ccl}
\hline 95\%CI & Mean(SD) & \multicolumn{1}{c}{ Variables } \\
\hline $28.31-31.31$ & $30.03(0.65)$ & Preparedness \\
$67.59-69.75$ & $68.67(0.55)$ & Perceived susceptibility \\
$71.65-74.61$ & $73.16(0.77)$ & Perceived severity \\
$76.15-78.87$ & $77.51(0.69)$ & Perceived benefits \\
$49.53-51.57$ & $50.55(0.52)$ & Perceived barriers \\
$46.46-65.67$ & $66.57(0.45)$ & Cues to action \\
$59.71-61.87$ & $60.79(0.55)$ & Self-Efficacy \\
$56.21-59.02$ & $57.61(0.71)$ & Earthquake performance awareness \\
\hline
\end{tabular}

Table 3. Determining the Relationship between Earthquake Preparedness and Demographic Variables of Participants by Independent T-Test and Analysis of Variance

\begin{tabular}{|c|c|c|c|c|}
\hline $\mathrm{P}$-value & Standard error & Mean & & Variables \\
\hline \multirow[t]{2}{*}{$<0.001$} & 0.781 & 30.560 & female & Sex \\
\hline & 1.281 & 29.004 & Male & \\
\hline \multirow[t]{2}{*}{$<0.001$} & 0.827 & 31.05 & Yes & Homeowner \\
\hline & 1.084 & 27.961 & No & \\
\hline \multirow[t]{2}{*}{$<0.001$} & 0.693 & 30.182 & Married & Marriage statue \\
\hline & 1.903 & 28.740 & Unmarried & \\
\hline \multirow[t]{2}{*}{$<0.001$} & 0.715 & 30.951 & Yes & Earthquake experience \\
\hline & 1.686 & 25.825 & No & \\
\hline \multirow[t]{2}{*}{$<0.001$} & 2.461 & 35.151 & Yes & Destructive earthquake \\
\hline & 0.685 & 29.888 & No & experience \\
\hline \multirow[t]{5}{*}{0.216} & 3.252 & 30.511 & $<20$ & Age \\
\hline & 1.246 & 30.971 & $21-30$ & \\
\hline & 1.103 & 31.265 & $31-40$ & \\
\hline & 1.446 & 29.541 & $41-50$ & \\
\hline & 1.705 & 26.834 & $>50$ & \\
\hline \multirow[t]{6}{*}{$<0.001$} & 1.194 & 25.116 & illiterate & Educational level \\
\hline & 1.300 & 27.574 & Elementary & \\
\hline & 1.396 & 27.336 & Secondary school & \\
\hline & 1.172 & 29.368 & High school & \\
\hline & 1.509 & 33.810 & Diploma & \\
\hline & 1.436 & 34.774 & Academic & \\
\hline \multirow[t]{6}{*}{$<0.001$} & 1.224 & 26.595 & Very poor & Economic statue \\
\hline & 1.239 & 25.272 & Poor & \\
\hline & 1.008 & 33.385 & Moderate & \\
\hline & 3.212 & 40.093 & Good & \\
\hline & 4.700 & 32.909 & Very good & \\
\hline & 0.813 & 30.668 & With yard & Residential type \\
\hline \multirow[t]{4}{*}{0.058} & 1.568 & 32.699 & Apartment & \\
\hline & 1.473 & 26.173 & Leased & \\
\hline & 5.586 & 31.076 & Mortgage & \\
\hline & 8.22 & 31 & Governmental & \\
\hline
\end{tabular}


Table 4. Determine the Relationship between Earthquake Preparedness and Study Variables Using Stepwise Linear Regression

\begin{tabular}{ccccl}
\hline \multicolumn{2}{c}{$95 \%$ CI } & p-value & Regression coefficient & \multicolumn{1}{l}{ Variables } \\
Lower $\quad$ upper & & & \\
\hline-0.106 & 0.116 & 0.931 & 0.005 & Perceived susceptibility \\
-0.087 & 0.046 & 0.554 & -0.020 & Perceived severity \\
$-\quad 0.214$ & -0.036 & 0.006 & -0.125 & Perceived benefits \\
$-\quad 0.047$ & 0.169 & 0.267 & 0.060 & barriers Perceived \\
0.1970 .439 & 0.001 & 0.318 & Cues to action \\
0.1370 .369 & 0.001 & 0.253 & Self-efficacy \\
$-0.113 \quad 0.016$ & 0.146 & 0.048 & Awareness \\
$0.854 \quad 2.733$ & 0.001 & 1.793 & Education \\
-1.337 & 6.459 & 0.198 & 2.561 & Earthquake experience \\
$-\quad 0.22$ & 3.182 & 0.053 & 1.580 & Economic statue \\
-4.151 & -0.783 & 0.004 & -2.467 & Residential type \\
-2.479 & -0.251 & 0.016 & -1.365 & Household size \\
12.843 & 2.466 & 0.004 & 7.855 & Destructive earthquake \\
& & & & experience \\
\hline
\end{tabular}

